\title{
Sources and Patterns of Diversity in Plant-Pathogenic Fungi
}

\author{
J. J. Burdon and J. Silk
}

Centre for Plant Biodiversity Research, Division of Plant Industry, CSIRO, P.O. Box 1600, Canberra, A.C.T. 2601, Australia. Accepted for publication 11 April 1997.

Plant-pathogenic fungi include a very large and heterogeneous group of organisms that occupy positions of great importance in both agriculture and natural plant communities. They show an enormous diversity in life-history strategies and the ways in which they interact with their hosts. These interactions range from species that establish perennial, systemic infections that castrate their hosts to pathogens that kill their hosts with considerable rapidity to pathogens that form discrete lesions whose individual effects are very limited (9). Many pathogenic fungi can survive for long periods of time on dead host tissue or saprophytically in soil; others rely entirely on living host cells for sustenance. Collectively, the pathogens can attack virtually any plant part, although individually they may be highly specialized. As a consequence, the range of pathogens found on different hosts also shows considerable diversity that may be associated with the evolutionary history of their hosts (16) or ecological criteria like the host's architectural complexity or the extent of the pathogen's natural range (35).

Understanding the role pathogens play in shaping the genetic structure of plant populations and communities requires an understanding of the pathogens' diversity, their origins, and the evolutionary interplay that occurs between pathogens and their hosts. Here we review sources of variation that contribute to the diversity of pathogen populations and some of the mechanisms whereby this diversity is maximized and maintained.

\section{ORIGINS OF DIVERSITY}

As is common with most organisms, plant-pathogenic fungi rely on the processes of mutation and recombination as the ultimate source of genetically based variation (Fig. 1). Within a species, gene flow between populations supplements these processes as propagules spread from one epidemiological area to another and from one deme to the next. Studies of a wide variety of fungal pathogens have highlighted the importance of some of the mechanisms behind these broad groupings as sources of diversity. Rarely, however, have these studies addressed the way in which these mechanisms intermesh to generate the overall variation encountered within a species.

Here we focus on understanding the extent of variation and genotype diversity in various populations of Puccinia graminis $\mathrm{f}$. sp. tritici (the wheat stem rust pathogen) $-P$. graminis $\mathrm{f}$. $\mathrm{sp}$. tritici being one of only a few species for which sufficient information is available to permit such an integrative approach. However, given the enormous range of life styles, growth forms, cellular organization, and cytological patterns that are apparent among plantpathogenic fungi, no one fungal species can serve as a model for all others. A range of mechanisms have been encountered in other pathogens that have yet to be observed in $P$. graminis f. sp. tritici

Corresponding author: J. J. Burdon; E-mail address: J.Burdon@pi.csiro.au

Publication no. P-1997-0515-01V

(C) 1997 The American Phytopathological Society (or that may never be possible in this species). Such mechanisms are illustrated as appropriate to further demonstrate the complex web whereby variation may be generated. Furthermore, for all mechanisms, additional examples are given to emphasize their significance and widespread contribution to variation in fungal systems.

\section{Migration and Gene Flow}

Of the three broad sources of variation in pathogen populations, gene flow is perhaps the simplest, although its contribution to diversity may be underestimated. The process of migration leading to the founding of new pathogen populations in areas in which they previously were absent has been recorded on many occasions (e.g., the introduction of Cryphonectria parasitica to North America, Phytophthora infestans to Europe, and Puccinia striiformis to Australia). However, where a pathogen population already exists, the recognition of such events tends to be restricted to instances that lead to obvious shifts in the genetic structure of the recipient deme.

Changes in the wheat stem rust flora in Australia over the past 50 years provide a clear picture of the contribution that longdistance gene flow can make to the genotypic diversity of populations. The original introduction of $P$. graminis $\mathrm{f}$. $\mathrm{sp}$. tritici into Australia probably occurred after European settlement (1780s). Since that time, sexual recombination has been prevented by the absence of the alternate sexual host, Berberis spp. As a consequence, the pathogen population has developed largely as a series of clonal lineages that have each expanded from founding ancestral isolates to produce more than 100 pathotypes (40; R. F. Park and R. A. McIntosh, unpublished data). These pathotypes have a virulence range that reflects the resistance-gene deployment strategies used in wheat in Australia over the period. Against this background, three major, abrupt changes in virulence profiles have been identified (40) (Fig. 2). In two of these cases (lineages II and IV; Fig. 2), the most parsimonious explanation for the observed shifts in pathogenicity is long-distance migration. Thus, the founding pathotype of lineage II (pathotype 21-0) differed from that of the extant lineage (I) by virulence to eight resistance genes, whereas that of lineage IV has a distinctive combination of virulences on the Australian supplementary differential series (cultivars with resistance genes $\operatorname{Sr} 6,7 b, 8 a, 9 b, 11$, and 17). Subsequent work has demonstrated a further range of genetically based, isozyme allele or random amplified polymorphic DNA (RAPD) band differences that are specific to either lineage I or pathotype 21-0 (12; J. Silk, unpublished data), confirming the latter's migrant origin. Lineages II and IV have identical isozyme phenotypes but show marked dissimilarity in RAPD patterns (22/268 bands different; J. Silk, unpublished data). In both of these cases, molecular markers have confirmed suspicions based on major virulence differences. Similar abrupt changes in pathogenicity, aggressiveness, and mating type have been observed in other pathogens, including Phytophthora infestans in Europe (19) and Ophiostoma novo-ulmi in Europe and North America (7).

Clearly, the use of virulence markers to identify the arrival of isolates of exotic origin will restrict recognition of such migration events to those in which the migrant is sufficiently different from 
the indigenous population. Indeed, information recently obtained from a detailed molecular survey of the Australian $P$. graminis $\mathrm{f}$. sp. tritici lineages clearly shows the occurrence of other gene flow events that have not been recognized previously. Thus, in lineage IV two closely related pathotypes (194-1,2,3,5,6 and 326-1,2,3,5,6) that were detected within 9 months of each other and that differ in virulence only for host resistance gene $S r 7 b$ have been shown to possess distinct, although related, RAPD patterns (12/268 band differences; J. Silk, unpublished data). This indicates that two migration events, either concurrent or separate but reasonably close in time, founded lineage IV.

Estimation of the frequency of such cases of "cryptic" migration will always be extremely difficult for any pathogen but es- pecially for those lacking a detailed history of past virulence patterns. For example, in a natural host-pathogen system involving the rust Melampsora lini, a migrant pathotype that appeared in one population was identified initially only by the chance detection of a distinctive isozyme phenotype during a routine population screen (J. J. Burdon, unpublished data). However, in at least some wild host-pathogen systems, extinction and recolonization events occur at noticeable frequencies $(4,10)$, suggesting that migration and subsequent gene flow play an important role in contributing to genotype diversity in pathogen populations. This is the case especially when pathogen populations are small, and simple mutation is unable to substitute for the advantages of sexual reproduction (24).

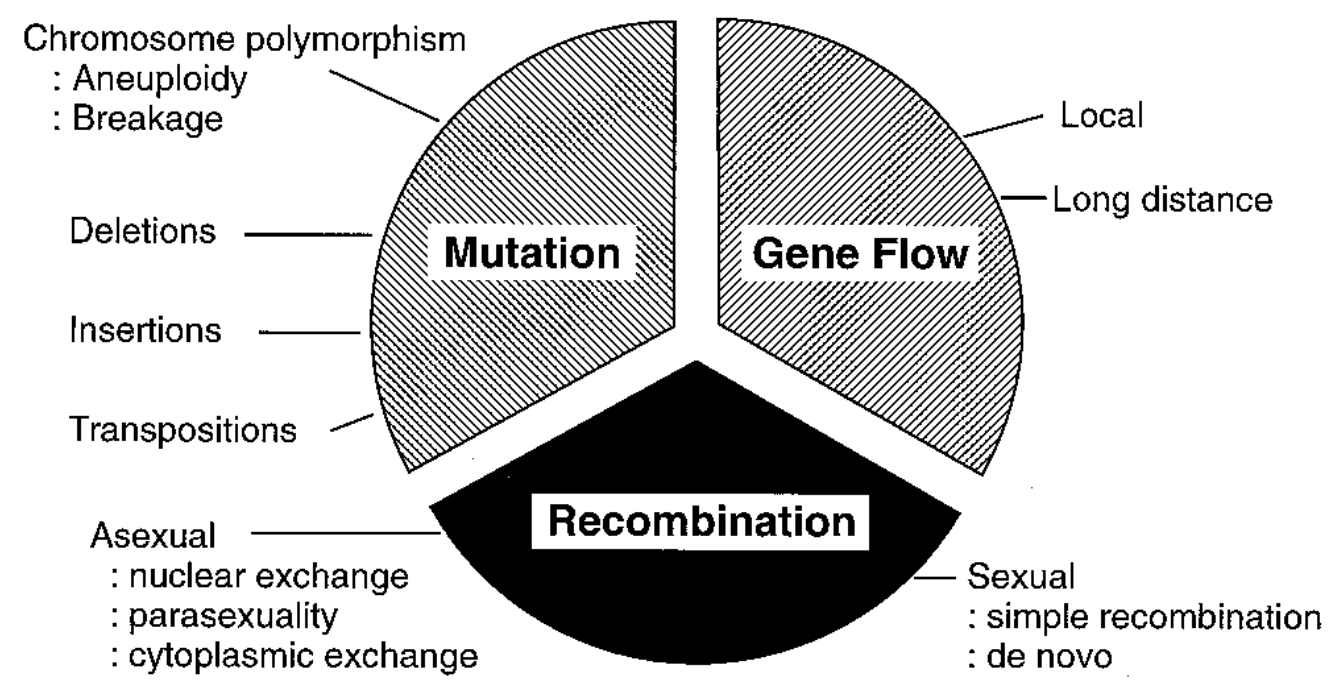

Fig. 1. Sources of gene and genotype diversity in pathogen populations.

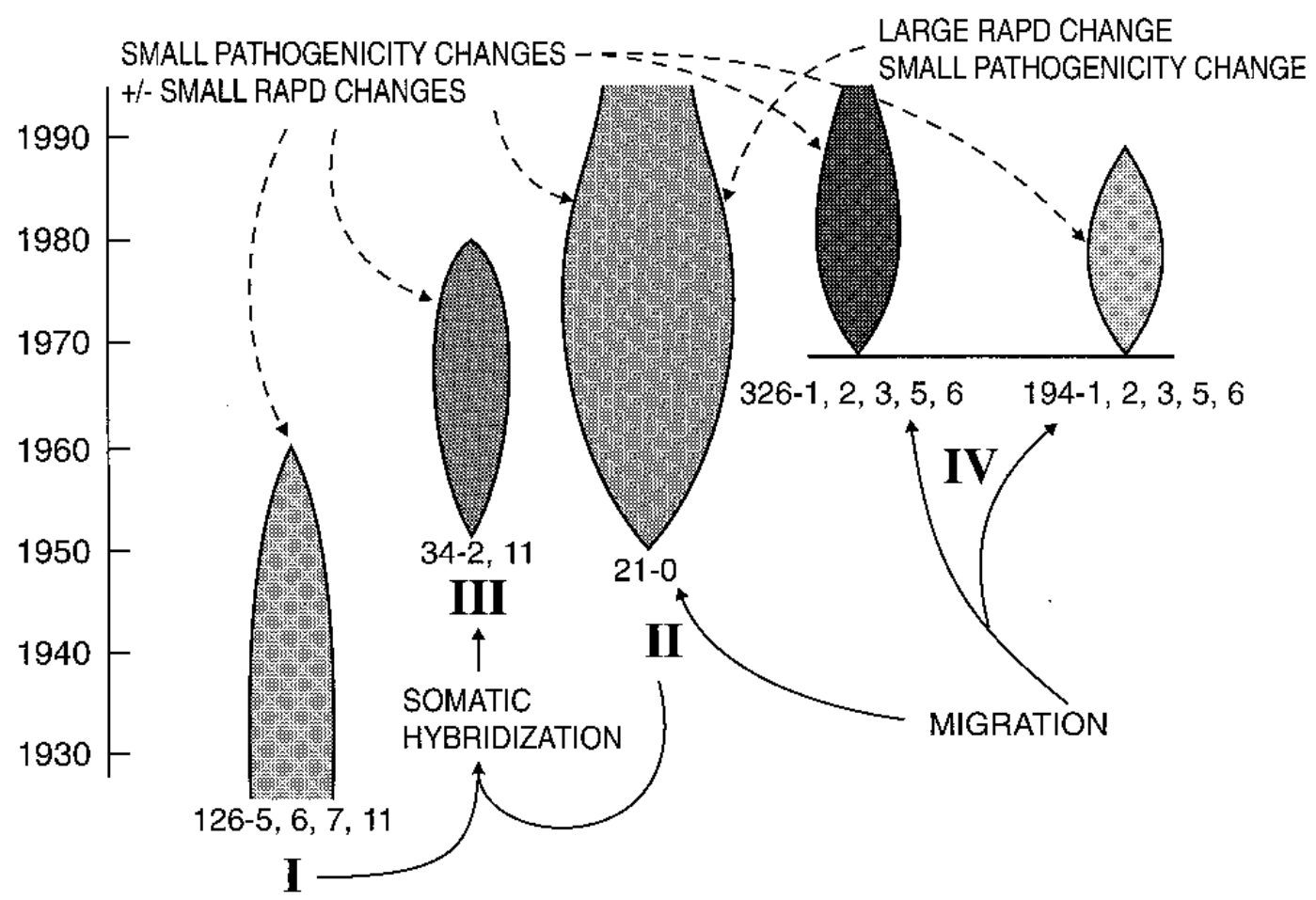

Fig. 2. Diagrammatic representation of the origin and structure of the Australian Puccinia graminis f. sp. tritici population. I, II, III, and IV refer to separate lineages within the population. The details are discussed in text. Pathotypes 126-5,6,7,11; 21-0; and 34-2,11 are the founders of lineages I, II, and III, respectively. Pathotypes 194-1,2,3,5,6 and 326-1,2,3,5,6 appeared within 9 months of each other and are assumed to have a common, although unexplained, origin (39). The historical duration of each lineage is represented diagrammatically by the shaded areas, the size of which provides a general guide to the relative importance of each. Solid arrows indicate the origin of lineages; dashed arrows indicate the associations between pathogenicity and molecular markers. 


\section{Recombination}

Recombination in plant pathogens occurs either through sexual reproduction or through a process of somatic hybridization, in which nuclear and cytoplasmic material may be exchanged. In turn, nuclear exchange may be followed by nuclear fusion and recombination (parasexual cycle). All of these mechanisms may generate increased genotypic diversity in a pathogen population, but their importance varies both within and among species.

Sexual recombination. The contrast between different populations of $P$. graminis f. sp. tritici in the United States powerfully demonstrates the contribution sexual recombination makes to population diversity. In the Pacific Northwest, sexual recombination occurs annually, leading to the generation of an enormous number of incipient clonal lineages, each with a distinctive genotype for markers such as isozyme and virulence pattern. A sample of 427 isolates collected from the Pacific Northwest population in 1975 contained 100 distinct pathotypes (33). Among a subsample of 92 of those isolates (15), 61 pathotypes and 80 isozyme phenotypes were detected. No two isolates with the same multilocus isozyme phenotype had the same combination of virulence genes.

When the possibility of sexual recombination is removed from such an interaction, genetic diversity within populations falls dramatically. Thus, further east, in the Great Plains of the United States, marked changes in the genotypic diversity of the P. graminis f. sp. tritici population are associated with the virtual eradication of barberry during the late 1920s (33). Prior to barberry eradication more than 17 pathotypes were detected routinely on a yearly basis. Since that time, the number has fallen markedly; only six to seven pathotypes are now found on a regular basis (33). More interestingly, however, the pathotypes that now occur in the Great Plains can be grouped into a total of nine clonal lineages. Each lineage is represented by a few pathotypes that differ by only 1 or 2 specificities; on the other hand, with one exception, lineages differ from one another by an average of 11 specificities and various isozyme markers $(14,33)$.

On a considerably compressed time scale, this pattern of sexual recombination, which gives rise to a plethora of recombinant genotypes, the most fit of which then dominate an asexually reproducing population with an ever declining diversity of clonal lineages, is played out on a yearly basis in a wide variety of pathogen populations. For example, cyclical patterns in both the absolute number of pathotypes and overall diversity of populations of Erysiphe graminis f. sp. hordei have been detected as the pathogen switches between sexual and asexual modes of reproduction $(43,44)$. At the other extreme, on time scales that may run for decades or even centuries, the consequences of these behaviors are found in the frequent dominance of just a few clones of rootrotting pathogens, like Armillaria, over hectares of forest.

In many fungi, mechanisms of vegetative incompatibility serve to further enhance the diversity generated through sexual recombination by ensuring at least some outcrossing (5). The effects of such mechanisms are particularly well demonstrated in population processes occurring in $O$. novo-ulmi, $C$. parasitica, Heterobasidion annosum, and Armillaria species. For example, at the beginning of an epidemic of $C$. parasitica, the number of cankers rose from 12 to 272 over 4 years (1). Although these cankers were dominated by one vegetative incompatibility genotype that was spread by clonal propagation, the advantage gained in successful sexual reproduction increased the number of vegetative incompatibility types from 6 to 48 (1).

Finally, although sexual recombination usually is seen as a mechanism whereby existing characters are reassorted, a recent study of the bacterial plant pathogen Xanthomonas citri found that entirely new virulence specificities were generated through intragenic recombination (45). Although this phenomenon has yet to be reported in fungal pathogens, its occurrence in the Xanthomonas system and in maize, where new resistance specificities are generated (32), suggests a similar mechanism may well occur in fungi.

Somatic recombination and exchange. At its simplest, somatic hybridization involves the exchange of nuclei between anastomosing fungal hyphae. In the dikaryotic basidiomycetes, two genetically different nuclei normally exist together in a stable state, and this exchange process can generate a maximum of two new combinations of characters; in the lower fungi, where the cytoplasm is continuous, many more combinations are potentially possible. Further variation may be generated when nuclear exchange is followed by nuclear fusion, mitotic recombination, and subsequent nonmeiotic reassortment of chromosomes by haploidization (the parasexual cycle). The intimate connections formed between distinct individuals during anastomosis also raise the possibility of an exchange of cytoplasmic organelles, plasmids, viruses, and extranuclear DNA.

The contribution that these processes make to fungal variation is difficult to assess. Controlled laboratory studies have demonstrated simple nuclear exchange in E. graminis (26). To date, however, evaluation of the role of nuclear exchange in field populations often has been prevented by a lack of appropriate genetic markers. Despite this difficulty, two clear examples of somatic recombination can be found in the evolutionary history of $P$. graminis f. sp. tritici in Australia. The first example occurred during the early 1950s, shortly after lineage II (Fig. 2) was established (41). Nuclear exchange between a founding pathotype of that lineage (pathotype 21-0) and one of the pathotypes of the existing rust flora (pathotype 126-5,6,7,11) resulted in a new pathotype (pathotype $34-2,11$ ) that subsequently gave rise to a new lineage (III). This lineage persisted in the population for 30 years, during which time more than 30 distinct pathotypes arose. Comparison of the multilocus isozyme phenotypes of pathotype 34-2,11 and its putative parents confirmed its origin as the product of a simple nuclear exchange event (12). A similar, but less apparent, hybridization event also has been detected within lineage II (Fig. 2), where one pathotype (116-4,5), classed as a member of lineage II based on its virulence profile, possesses a PCR-IGS-1 phenotype that suggests $P$. graminis f. sp. secalis contributed to its parentage via somatic hybridization (J. Silk, unpublished data).

Somatic hybridization also may involve wider crosses, and a similar interaction between two distinct species of poplar rust $(M$. larici-populina and $M$. medusae) in New Zealand, where the sexual stage of these rusts has not been reported, apparently has generated a hybrid rust with a novel combination of virulence specificities (34). The parents of this hybrid are naturally geographically isolated from each other (Europe and North America, respectively), and this result points to at least one way in which new pathogen species may arise.

None of these examples provides evidence of the operation of the full parasexual cycle. However, a series of studies involving deliberate coinoculation of susceptible hosts with pathotypes of $P$. graminis f. sp. tritici $(17,41)$, P. coronata (3), and Rhynchosporium secalis (29) recorded the appearance of a range of new pathotypes. Unfortunately, with the exception of the R. secalis study, the recombinant nature of the novel pathotypes was not confirmed by codominant genetic markers, leaving open the possibility that contamination was a source of some, if not all, of the variation observed. Indeed, even in the $R$. secalis experiment, the markers were not very good and certainly not sufficient to prove the occurrence of parasexual recombination. Clearly, it will be very difficult to obtain convincing evidence of the operation of the parasexual cycle in field situations where many fungal phenotypes already exist.

In contrast, evidence of cytoplasmic exchange during anastomosis is relatively common. This may result in the horizontal transmission of cytoplasmic organelles, which, although they sometimes provide an evolutionary trail for phylogeneticists to follow (mtDNA markers; [39]), have no discernible effect on the pheno- 
type of the pathogen. Alternatively, these events may be marked by a change in pathogen phenotype that is reflected in the genotypic diversity and dynamics of the pathogen population. Particularly good examples of this pattern of response are seen in the switch from hyper- to hypovirulence that is associated with the acquisition of dsRNA virus-like particles in a number of fungal pathogens, including C. parasitica (37), O. novo-ulmi (7), and Sclerotinia sclerotiorum (4).

\section{Mutation}

The extent to which mutation contributes to the effective diversity of populations is affected by the inherent rate of mutation, the ploidy level of the pathogen (haploid versus diploid or dikaryotic), the size of the pathogen population, and the selective advantage conferred by the mutant phenotype (8). Despite this complexity, spontaneous mutation is a powerful source of novel variation in many pathogen populations and is undoubtedly the origin of the majority of new pathotypes of $P$. graminis $\mathrm{f}$. sp. tritici that have arisen in the various clonal lineages in Australia or in the Great Plains of the United States over the past 50 or more years. Most variants arising in these lineages differ from preexisting pathotypes by only one or two virulence genes and may be interpreted reasonably as having arisen through point or small deletions. Similar patterns are apparent within the U.S. Phytophthora infestans population, where rapid evolution of virulence within clonal lineages has generated much of the genotypic diversity observed in the field (20), and that of Puccinia striiformis in Australia (42).

Although larger changes in virulence often are ascribed to other factors (migration or hybridization), they also may be caused by mutational events, especially if the different genes affected are closely linked, or if inhibitor genes are present. Both of these possibilities have been demonstrated in the case of virulence in $M$. lini (23). Other mutational events may involve insertions into or transpositions of the existing coding sequence, which in turn may have variable phenotypic effects.

On an even larger scale, chromosome instability and shedding (46) clearly are mutation events that may have dramatic effects on the phenotypic diversity of pathogen populations. Karyotype instability is a source of variation in both sexually and asexually reproducing fungi. In sexual fungi, recombination during meiosis may lead to significant karyotype variation due to the random assortment of parental homologues of different sizes, as has been shown in Leptosphaeria maculans (31). However, chromosome polymorphism is particularly widespread in imperfect fungi, in which chromosome aberrations of many kinds may accumulate without the purging effects of meiosis (22). The consequences of this variation are unclear, but the range of karyotypes observed in various fungi (including differences in both chromosome size and number) suggest that, under some conditions, such changes may be selectively neutral. Equally, however, the new linkage combinations that become possible with such changes also may be advantageous, allowing adaptation to new environments (46). Indeed, in Nectria haematococca the loss of one chromosome has been associated with a marked change in pathogenicity, with the new karyotype showing pathogenicity against previously immune host species $(27,38)$. In other fungi, development of marked differences in chromosome number between different isolates (e.g., 15 to 19 chromosomes in Ustilago hordei [25]) or the occurrence of significant numbers of minichromosomes have no detectable effect.

\section{DYNAMICS OF DIVERSITY}

The interplay of selection, genetic drift, migration, and mutation has a major effect on the genetic structure and diversity of all pathogen populations. The relative roles of these factors may change markedly between different pathogen-host associations, between stages in the epidemiological cycle, and between associations in agricultural and natural ecosystems. In doing so, they may result in marked differences in the genotypic diversity of comparable fungal pathogens and, certainly, in the distribution of genotypic diversity within and among different populations. One factor of particular significance in this interactive process is the size of pathogen populations. This is the case especially for obligate pathogens for which the patchy distribution of natural host populations tends to result in fungal populations that show large amplitudes in size, relatively local and frequent extinctions, and asynchrony in the dynamics of neighboring demes $(2,10)$. In turn, provided such patchiness is accompanied by restricted movement of the pathogen, the potential genetic consequence of these features is one of considerable genotypic diversity among individual pathogen demes as they each respond asynchronously to differences in the local selective environment. This "metapopulation" view of the evolution and diversity of pathogen populations $(9,36)$ differs markedly from models that are based on evolution in a uniform environment where mutation rates and frequency-dependent selection are the most important processes.

\section{Genetic Drift and Migration}

Studies of natural pathogen populations that are sufficiently detailed to show some of the potential diversifying consequences of this patchiness in natural pathogens are extremely limited. However, circumstantial evidence is available in local populations of $M$. lini parasitizing a series of small populations of its host (Linum marginale) in southern Australia (11,21; J. J. Burdon, unpublished data). Details of three of these populations, a maximum of $2.7 \mathrm{~km}$ apart, show examples of considerable temporal change in the occurrence and relative frequency of particular pathotypes (Fig. 3). Thus, although the population at Kiandra was dominated by pathotype A in both 1988 and 1989, the relative frequency of several other pathotypes changed, with pathotype $\mathrm{H}$ disappearing and both pathotypes $\mathrm{N}$ and AR increasing markedly. In these pat-

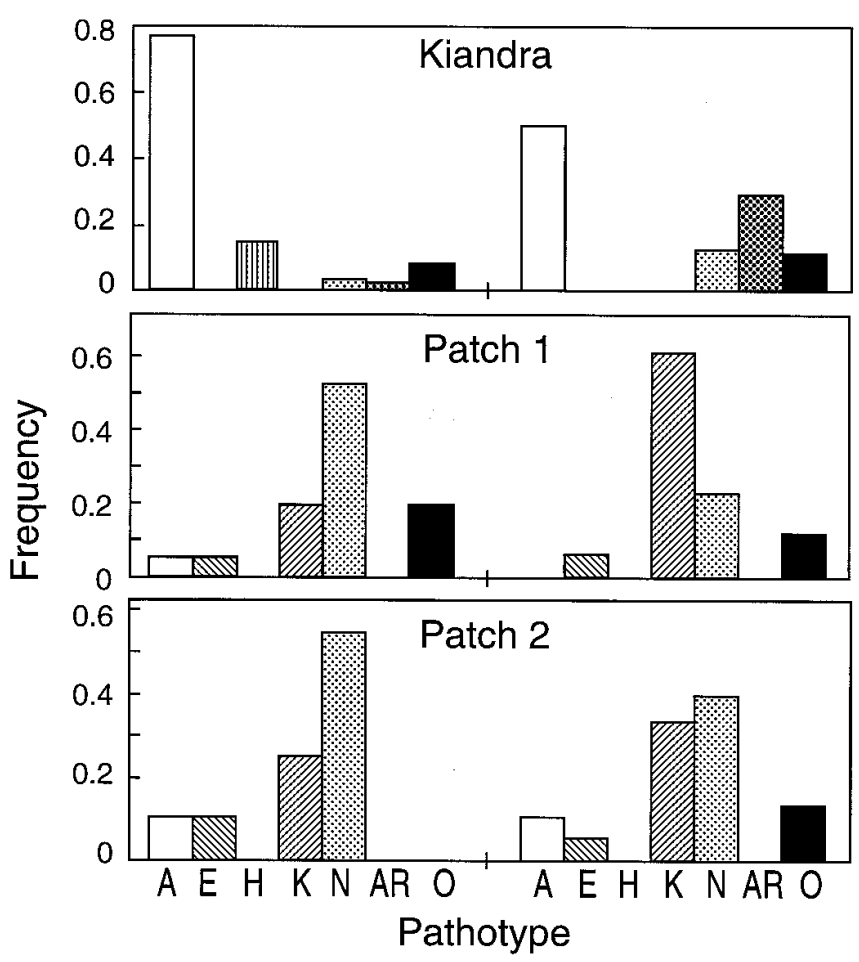

Fig. 3. Temporal and spatial variation in the pathotypic structure of three local populations of Melampsora lini that occurred in Australia in 1988 and 1989. Pathotypes A, E, H, K, N, and AR were determined by their response on a differential set of Linum marginale lines. Column $\mathrm{O}$ to the extreme right of both years represents a pooling of all other pathotypes detected (9; J. J. Burdon and A. M. Jarosz, unpublished data). 
terns, pathotype AR is of particular interest, because virulence and isozyme data clearly indicate a migrant origin (it was first detected as a single isolate in 1988). Other similar changes in the frequency of particular pathotypes in patches 1 and 2, for example the loss of pathotype A from patch 1 and the appearance of a number of other pathotypes in patch 2, in 1989, and the marked change in the relative frequency of pathotypes $\mathrm{K}$ and $\mathrm{N}$ are consistent with the consequences of local drift during over-wintering declines in the size of the pathogen population.

\section{Selection}

Evidence of host-induced selection among the three populations of $M$. lini is limited. Patches 1 and 2 were characterized by low levels of host resistance $(<15 \%$ individuals resistant to any pathotype), whereas at Kiandra $>95 \%$ of individuals carried resistance to at least some pathotypes (21). However, with the exception of pathotype $\mathrm{K}$, the relative frequency of different pathotypes is not a good reflection of host resistance.

Despite this result, it is inevitable that a layer of selection is imposed on individual pathogen demes by a range of biotic and abiotic factors. Host-related factors (major resistance genes; variation in presence, quantity, and relative balance of phenolic compounds; variations in morphology, etc.) frequently are seen as important, but their effect on population diversity is unpredictable. In a uniform environment, selection may favor particular genotypes (thus reducing diversity). However, in more natural situations, where selectively important host variation may occur within individual demes, selection may enhance diversity. Such a possibility is shown by a recently published assessment of $E$. graminis f. sp. hordei in Europe where "hot spots" of pathotypic diversity were found in the former East Germany and Denmark - two regions where varietal mixtures involving the intimate deployment of many racespecific resistance genes have found considerable use (28). Equally, in interactions involving pathogen movement between different host species, the overall genotypic diversity detected may result from a complex of pathogen-alternative host species interactions. In Australia, detailed assessments of the interplay between P. graminis f. sp. avenae and $P$. coronata, their wild hosts Avena barbata, A. fatua, and A. ludoviciana, and the crop species A. sativa and A. strigosa have demonstrated this possibility. The number of pathotypes, their mean virulence, and their geographic patterns of occurrence all implicate selection on wild hosts as an important source of variation in the pathogen population as a whole $(13,30)$. Such interactions are even more extreme within the center of the evolution of these hosts, where pathogens like $P$. coronata sensu lato may parasitize more than 60 host species from a range of genera (18).

Pathogen-induced selection also may generate considerable variability within populations. Perhaps the best example of this phenomenon is seen in pathogens that possess a vegetative compatibility (vc) system. In these species, circumstances that favor the generation of new genotypes also favor the establishment, whether through mutation or migration, of new ve groupings. In $O$. novoulmi just such a selective force may be imposed by the d-factor-a virus-like cytoplasmic disease. This disease spreads readily through hyphal fusions between colonies of the same vc grouping and in conidia but is restricted strongly by vegetative incompatibility reactions and is absent from sexual spores (6). Given this disease advantage, and an additional frequency-dependent gain that accrues through opportunities for successful recombination with fungal isolates from different vc groupings, it is unsurprising that large numbers of $\mathrm{vc}$ groups have been identified in populations of a range of fungi with vc systems, including $C$. parasitica, $H$. annosum, and $O$. novo-ulmi $(1,6)$.

Viewing pathogens in a metapopulation context reinforces the importance of the ecological setting for developing any understanding of the generation and maintenance of diversity in pathogen populations. The temporal and spatial patchiness that results from the interplay of fungal life history characters (e.g., off-season survival ability) and host population size, predictability, and distribution induces asynchrony in pathogen behavior among demes and affects the probability of local drift, extinction, and recolonization. In these situations, drift and migration are opposing forces that act, respectively, to reduce and increase within-population genotype diversity, while simultaneously increasing and decreasing between-population variability. The combined effect of these forces may lead to the development of a dynamic, ever-changing patchwork of distinct, individual pathogen demes-a feature that is likely to be strengthened further by differences in the local selective biotic and abiotic environment.

\section{LITERATURE CITED}

1. Anagnostakis, S. L., and Kranz, J. 1987. Population dynamics of Cryphonectria parasitica in a mixed-hardwood forest in Connecticut. Phytopathology 77:751-754.

2. Antonovics, J., Thrall, P. H., Jarosz, A. M., and Stratton, D. 1994. Ecological genetics of metapopulations: The Silene-Ustilago plant-pathogen system. Pages 146-170 in: Ecological Genetics. L. A. Real, ed. Princeton University Press, Princeton, NJ.

3. Bartos, P., Fleischmann, G., Samborski, D. J., and Shipton, W. A. 1969. Studies on asexual variation in the virulence of oat rust, Puccinia coronata f. sp. avenae and wheat leaf rust, Puccinia recondita. Can. J. Bot. 47:1383-1387.

4. Boland, G. 1992. Hypovirulence and double-stranded RNA in Sclerotinia sclerotiorum. Can. J. Plant Pathol. 14:10-17.

5. Brasier, C. M. 1984. Inter-mycelial recognition systems in Ceratocystis ulmi: Their physiological properties and ecological importance. Pages 451-497 in: The Ecology and Physiology of the Fungal Mycelium. D. H. Jennings and A. D. M. Rayner, eds. Cambridge University Press, Cambridge.

6. Brasier, C. M. 1988. Rapid changes in genetic structure of Ophiostoma ulmi. Nature (Lond.) 332:538-541.

7. Brasier, C. M. 1990. The unexpected element: Mycovirus involvement in the outcome of two recent pandemics, Dutch elm disease and chestnut blight. Pages 289-307 in: Pests, Pathogens and Plant Communities. J. J. Burdon and S. R. Leather, eds. Blackwell Scientific Publications, Oxford.

8. Burdon, J. J. 1992. Genetic variation in pathogen populations and its implication for adaptation to host resistance. Pages 41-56 in: Durability of Disease Resistance. Th. Jacobs and J. E. Parlevliet, eds. Kluwer Academic Publishers, Amsterdam.

9. Burdon, J. J. 1993. The structure of pathogen populations in natural plant communities. Annu. Rev. Phytopathol. 31:305-323.

10. Burdon, J. J., Ericson, L., and Müller, W. J. 1995. Temporal and spatial relationships in a metapopulation of the rust pathogen Triphragmium ulmariae and its host, Filipendula ulmaria. J. Ecol. 82:979-989.

11. Burdon, J. J., and Jarosz, A. M. 1992. Temporal variation in the racial structure of flax rust (Melampsora lini) populations growing on natural stands of wild flax (Linum marginale): Local versus metapopulation dynamics. Plant Pathol. 41:165-179.

12. Burdon, J. J., Marshall, D. R., Luig, N. H., and Gow, D. J. S. 1982. Isozyme studies on the origin and evolution of Puccinia graminis $\mathrm{f}$. sp. tritici in Australia. Aust. J. Biol. Sci. 35:231-238.

13. Burdon, J. J., Marshall, D. R., and Oates, J. D. 1992. Interactions between wild oats and cultivated oats in Australia. Proc. 4th Int. Oat Conf. A. R. Barr and R. W. Medd, eds. Int. Oat Conf. Commit. Adelaide 2:82-87.

14. Burdon, J. J., and Roelfs, A. P. 1985. Isozyme and virulence variation in asexually reproducing populations of Puccinia graminis and $P$. recondita on wheat. Phytopathology 75:907-913.

15. Burdon, J. J., and Roelfs, A. P. 1985. The effect of sexual and asexual reproduction on the isozyme structure of populations of Puccinia graminis. Phytopathology 75:1068-1073.

16. Clay, K. 1995. Correlates of pathogen species richness in the grass family. Can. J. Bot. 73(Suppl. 1):S42-S49.

17. Ellingboe, A. H. 1961. Somatic recombination in Puccinia graminis var. tritici. Phytopathology 51:13-14.

18. Eshed, N., and Dinoor, A. 1981. Genetics of pathogenicity in Puccinia coronata: The host range among grasses. Phytopathology 71:156-163.

19. Fry, W. E., Goodwin, S. B., Matuszak, J. M., Spielman, L. J., and Milgroom, M. G. 1992. Population genetics and intercontinental migrations of Phytophthora infestans. Annu. Rev. Phytopathol. 30:107-129.

20. Goodwin, S. B., Sujkowski, L. S., and Fry, W. E. 1995. Rapid evolution of pathogenicity within clonal lineages of the potato late blight disease fungus. Phytopathology 85:669-676.

21. Jarosz, A. M., and Burdon, J. J. 1991. Host-pathogen interactions in natural populations of Linum marginale and Melampsora lini: II. Local 
and regional variation in patterns of resistance and racial structure. Evolution 45:1618-1627.

22. Kistler, H. C., and Miao, V. P. W. 1992. New modes of genetic change in filamentous fungi. Annu. Rev. Phytopathol. 30:131-152.

23. Lawrence, G. J. 1988. Melampsora lini, rust of flax and linseed. Adv. Plant Pathol. 6:313-331.

24. Maynard Smith, J. 1968. Evolution in sexual and asexual populations. Am. Nat. 102:469-473.

25. McCluskey, K., and Mills, D. 1990. Identification and characterization of chromosome length polymorphisms among strains representing fourteen races of Ustilago hordei. Mol. Plant-Microbe Interact. 3:366-373.

26. Menzies, J. G., and MacNeill, B. H. 1986. Asexual recombination in Erysiphe graminis f. sp. tritici. Can. J. Plant Pathol. 8:400-404.

27. Miao, V., and VanEtten, H. D. 1989. Non-transmittance through meiosis of a gene for pisatin demethylase in Nectria haematococca MP VI is correlated with a change in electrophoretic karyotype. J. Cell. Biochem. Suppl. 13E:22.

28. Müller, K., McDermott, J. M., Wolfe, M. S., and Limpert, E. 1996. Analysis of diversity in populations of plant pathogens: The barley powdery mildew pathogen across Europe. Eur. J. Plant Pathol. 102:385-395.

29. Newman, P. L., and Owen, H. 1985. Evidence of asexual recombination in Rhynchosporium secalis. Plant Pathol. 34:338-340.

30. Oates, J. D., Burdon, J. J., and Brouwer, J. B. 1983. Interactions between Avena and Puccinia species. II. The pathogens: Puccinia coronata Cda. and $P$. graminis f. sp. avenae Eriks. and Henn. J. Appl. Ecol. 20:585-596.

31. Plummer, K. M., and Howlett, B. J. 1995. Inheritance of chromosomal length polymorphisms in the ascomycete Leptosphaeria maculans. Mol. Gen. Genet. 247:416-422.

32. Richter, T. E., Pryor, A. J., Bennetzen, J. L., and Hulbert, S. H. 1995. New rust resistance specificities associated with recombination in the Rpl complex in maize. Genetics 141:373-381

33. Roelfs, A. P., and Groth, J. V. 1980. A comparison of virulence phenotypes in wheat stem rust populations reproducing sexually and asexually. Phytopathology 70:855-862.
34. Spiers, A. G., and Hopcroft, D. H. 1994. Comparative studies of the poplar rusts Melampsora medusae, M. larici-populina and their interspecific hybrid M. medusae-populina. Mycol. Res. 98:889-903.

35. Strong, D. R., and Levin, D. A. 1979. Species richness of plant parasites and growth form of their hosts. Am. Nat. 114:1-22.

36. Thompson, J. N., and Burdon, J. J. 1992. Gene-for-gene coevolution between plants and parasites. Nature (Lond.) 360:121-125.

37. Van Alfen, N. K., Janes, R. A., Anagnostakis, S. L., and Day, P. R. 1975. Chestnut blight: Biological control by transmissible hypovirulence in Endothia parasitica. Science 189:890-891.

38. VanEtten, H., Funnell-Baerg, D., Wasmann, C., and McCluskey, K. 1994. Location of pathogenicity genes on dispensible chromosomes in Nectria haematococca MPVI. Antonie Leeuwenhoek 65:263-267.

39. Van Horn, R., and Clay, K. 1995. Mitochondria DNA variation in the fungus Atkinsonella hypoxylon infecting sympatric Danthonia grasses. Evolution 49:360-371.

40. Watson, I. A. 1980. Wheat and its rust parasites in Australia. Pages 129147 in: Wheat Sciences-Today and Tomorrow. L. T. Evans and W. J. Peacock, eds. Cambridge University Press, Cambridge.

41. Watson, I. A., and Luig, N. H. 1958. Somatic hybridization in Puccinia graminis var. tritici. Proc. Linn. Soc. N.S.W. 83:190-195.

42. Wellings, C. R., and McIntosh, R. A. 1990. Puccinia striiformis f. sp. tritici in Australasia: Pathogenic changes during the first ten years. Plant Pathol. 39:316-325.

43. Welz, G., and Kranz, J. 1987. Effects of recombination on races of a barley powdery mildew population. Plant Pathol. 36:107-113.

44. Welz, H. G., Nagarajan, S., and Kranz, J. 1990. Short-term virulence dynamics of Erysiphe graminis f. sp. hordei in a single epidemic on two susceptible barley cultivars. J. Plant Dis. Prot. 97:250-262.

45. Yang, Y. O., and Gabriel, D. W. 1995. Intragenic recombination of a single plant pathogen gene provides a mechanism for the evolution of new host specificities. J. Bacteriol. 177:4963-4968.

46. Zolan, M. E. 1995. Chromosome length polymorphism in fungi. Microbiol. Rev. 59:686-698. 